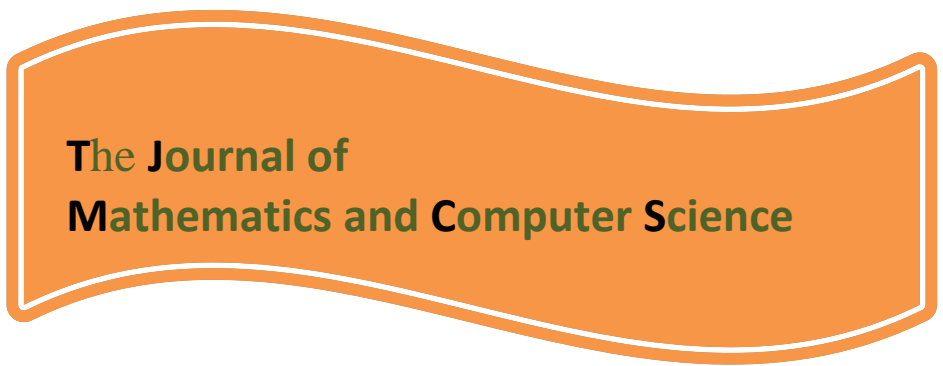

Available online at

http://www.TIMCS.com

The Journal of Mathematics and Computer Science Vol .2 No.3 (2011) 559-564

\title{
Comparing PID and Fuzzy Logic Control a Quarter-Car Suspension System
}

\author{
Nemat Changizi1, ${ }^{*}$, Modjtaba Rouhani² \\ Islamic Azad University, Gonabad Branch, \\ nemat.changizi@gmail.com \\ Islamic Azad University, Gonabad Branch, \\ m.rouhani@ieee.org
}

Received: August 2010, Revised: November 2010

Online Publication: January 2011

\begin{abstract}
The main aim of suspension system is to isolate a vehicle body from road irregularities in order to maximize passenger ride comfort and retain continuous road wheel contact in order to provide road holding. The aim of the work described in the paper was to illustrate the application of fuzzy logic technique to the control of a continuously damping automotive suspension system .The ride comfort is improved by means of the reduction of the body acceleration caused by the car body when road disturbances from smooth road and real road roughness. The paper describes also the model and controller used in the study and discusses the vehicle response results obtained from a range of road input simulations. In the conclusion, a comparison of active suspension fuzzy control and Proportional Integration derivative (PID) control is shown using MATLAB simulations.
\end{abstract}

Keywords: suspension system, a quarter-car model, fuzzy logic control, PID controller, spring and damper

${ }^{1, *}$ Corresponding author: Department of Electrical \& Control Engineering, Islamic Azad University of Gonabad Branch

${ }^{2}$ Assistant Professor, Islamic Azad University of Gonabad Branch 


\section{Introduction}

Automobile suspensions have for years consisted of a coil or leaf spring in parallel with a viscous damper. Inherent to these passive systems are a natural trade-off between ride comfort and road handling characteristics. Soft springs facilitate good ride characteristics at the expense of increased wheel motion and increased variations in dynamic tire loadings on rough roads. On the flip-side, good road handling characteristics and smaller motion is an attribute of larger spring rates. Therefore, spring rates must be chosen large enough to limit wheel motion and dynamic tire variations yet small enough to provide a comfortable ride. Through many years of experimentation and testing, this arrangement has evolved into a near optimal design. Hence, to further improve suspension that will be the focus of this research. Fuzzy logic controllers have been used in many applications, such as: cruise control, automatic transmissions, Sendai subway operation, coldrolling mills, self-parking model car, image stabilizer for video camera and a fully automated washing machine [1,2]. Given the proven diversity of fuzzy logic control, this technique was selected to control the active suspension. In [3], Cherry used a fuzzy logic controller to control a 47 degree of Freedom (DOF) multi body automotive suspension. By modeling the entire car, Cherry could analyze the vertical, pitch and roll response to selected inputs. For this research only vertical response will be evaluated using a 2 DOF model. Sufficient for developmental testing, a 2 DOF model incorporates the most important suspension characteristics while keeping computations simple. RO [4] uses a 2 DOF suspension model for the analysis of his fuzzy logic controller. Differing from R0, a much simpler rule base along with a wider range of input conditions is used for this study. The performance of the fuzzy logic active suspension was compared to a passive suspension and to a benchmark active suspension. A large number of different arrangements from semi-active to fully active schemes have been investigated [5,6,7,8,9]. $\operatorname{In}[10]$, a complete set of constraints was derived on the road and load disturbance response transfer functions and results on the choice of sensors needed to achieve these degrees of freedom independently were obtained for the quartercar model .The generalization of these results to half -and full-car models was then presented in[11]. In [12], it was shown that the road and load disturbance responses cannot be adjusted independently for any passive suspension applied to a quarter-car model. In this paper, an automatic suspension system for a quarter car is considered and a fuzzy logic controller is designed when the vehicle is experiencing any road disturbance, the vehicle body should not have large oscillations, and the oscillations should dissipate quickly. The road disturbance is simulated by a step input as a soft road test and rough road as a simulated to real way and the distance between the body mass and simulation mass is output of the system.

\section{Quarter-car suspension model}

In this paper, we are considering a quarter car model with two degrees of freedom. This model uses a unit to create the control force between body mass and wheel mass. 


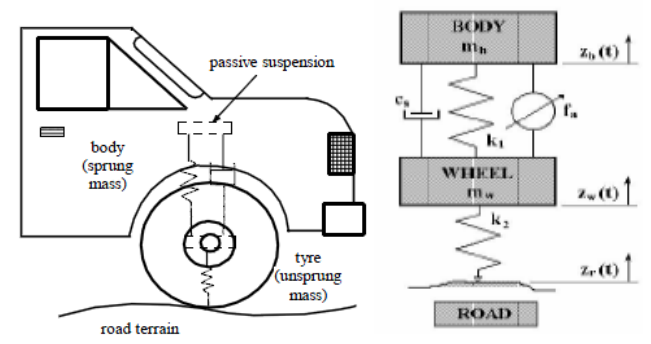

Figure 1. A quarter car representation of passive B .Quarter-car model

The motion equations of the car body and the wheel are as follows:

$$
\begin{aligned}
& \ddot{z}_{\mathrm{b}}=\frac{\mathrm{f}_{\mathrm{a}}-\mathrm{k}_{1}\left(\mathrm{z}_{\mathrm{b}}-\mathrm{z}_{\mathrm{w}}\right)-\mathrm{c}_{\mathrm{s}}\left(\dot{\mathrm{z}}_{\mathrm{b}}-\dot{\mathrm{z}}_{\mathrm{w}}\right)}{\mathrm{m}_{\mathrm{b}}} \\
& \ddot{\mathrm{z}}_{\mathrm{w}}=\frac{-\mathrm{f}_{\mathrm{a}}+\mathrm{k}_{1}\left(\mathrm{z}_{\mathrm{b}}-\mathrm{z}_{\mathrm{w}}\right)+\mathrm{c}_{\mathrm{s}}\left(\dot{\mathrm{z}}_{\mathrm{b}}-\dot{\mathrm{z}}_{\mathrm{w}}\right)-\mathrm{k}_{2}\left(\mathrm{z}_{\mathrm{w}}-\mathrm{z}_{\mathrm{r}}\right)}{\mathrm{m}_{\mathrm{w}}}
\end{aligned}
$$

with the following constants and variables are shown in under Table.

Table 1. QUARTER CAR PARAMETERS

\begin{tabular}{|c|c|c|}
\hline Parameters & Symbols & Quantities \\
\hline Body mass & $\mathrm{m}_{\mathrm{b}}$ & $250 \mathrm{~kg}$ \\
\hline Wheel mass & $\mathrm{m}_{\mathrm{w}}$ & $50 \mathrm{~kg}$ \\
\hline Stiffness of the body & $\mathrm{K}_{1}$ & $16 \mathrm{kN} / \mathrm{m}$ \\
\hline Stiffness of the wheel & $\mathrm{K}_{2}$ & $160 \mathrm{kN} / \mathrm{m}$ \\
\hline $\begin{array}{c}\text { Stiffness of the } \\
\text { damper }\end{array}$ & $\mathrm{C}_{\mathrm{s}}$ & $1.5 \mathrm{kN} . \mathrm{s} / \mathrm{m}$ \\
\hline
\end{tabular}

\section{State-space Model}

To model the road input let us assume that the vehicle is moving with a constant forward speed. Then the vertical velocity can be taken as a white noise process which is approximately true for most of real roadways. To transform the motion equations of the quarter car model into a space state model, the following state variables are considered:

$$
X=[x 1, x 2, x 3, x 4]^{T}
$$

where $\mathrm{x} 1=\mathrm{z}_{\mathrm{b}}-\mathrm{z}_{\mathrm{w}}$ is the body displacement, $\mathrm{x} 2=\mathrm{z}_{\mathrm{w}}-\mathrm{z}_{\mathrm{r}}$ is the wheel displacement, $\mathrm{x} 3=\dot{\mathrm{z}}_{\mathrm{b}}$ is the absolute velocity of the body, and $\mathrm{x} 4=\dot{\mathrm{z}}_{\mathrm{w}}$ is the absolute velocity of the wheel.Then the motion equations of the quarter car model for the active suspension can be written in state space form as follows:

$$
x=A \cdot x+B \cdot\left[\begin{array}{l}
f_{a} \\
\dot{z}_{r}
\end{array}\right]
$$


With

$$
A=\left[\begin{array}{cccc}
0 & 0 & 1 & -1 \\
0 & 0 & 0 & 1 \\
-64 & 0 & -6 & 6 \\
320 & -3200 & 30 & -30
\end{array}\right], B=\left[\begin{array}{cc}
0 & 0 \\
0 & -1 \\
0.004 & 0 \\
-0.02 & 0
\end{array}\right]
$$

where $\mathrm{f}_{\mathrm{a}}$ is the control force, $\mathrm{z}_{\mathrm{r}}$ is the road input displacement.

\section{Fuzzy logic controller}

The fuzzy logic controller used in the active suspension has three inputs: body Acceleration $\ddot{z}_{\mathrm{b}}$, body velocity $\dot{z}_{b}$, body deflection velocity $\dot{z}_{b}-\dot{z}_{w}$ and one output: desired actuator force $\mathrm{f}_{\mathrm{a}}$. The control system itself consists of three stages: fuzzification, fuzzy inference machine and defuzzification.

The fuzzification stage converts real-number (crisp) input values into fuzzy values while the fuzzy inference machine processes the input data and computes the controller outputs in cope with the rule base and data base. These outputs, which are fuzzy values, are converted into real-numbers by the defuzzification stage.

The rule base used in the active suspension system for one-half-car model is represented by 75 rules with fuzzy terms derived by modeling the designer's knowledge and experience that membership functions are triangular form. The body acceleration consists of two mode, the one mode has zero body acceleration so the control action was chosen to minimize the relative and the absolute body velocities only .The second mode, the body acceleration has positive or negative values so important to modify the control action to minimize it also. Thus the rules of the controller have the general form of:

$$
\operatorname{IF}\left(\dot{z}_{b}-\dot{z}_{w}=A\right) A N D\left(\dot{z}_{b}=B\right) A N D\left(\ddot{z}_{b}=C\right) \operatorname{THEN}\left(f_{a}=D\right)
$$

where $\mathrm{Ai}, \mathrm{Bi}, \mathrm{Ci}$ and $\mathrm{Di}$ are labels of fuzzy sets which are characterised by their membership functions. The output of the fuzzy controller is a fuzzy set of control. As a process usually requires a non-fuzzy value of control, a method of defuzzification called "centre of gravity method"(COG), is used here [13]:

$$
f_{a}=\frac{\int f * \mu_{D}(f) \cdot d f}{\int \mu_{D}(f) \cdot d f}
$$

where $\mu_{D}(f)$ is corresponding membership function. The actuator force $\left(f_{a}\right)$ is chosen to give \pm 6 $\mathrm{kN}$ as a maximum and minimum values.

\section{SIMULATION}

Simulation results of active suspension controlled by PID and Fuzzy control are compared in figure 2. results can be noticed that the fuzzy logic control provided good results than PID. 
Nemat Changizi, Modjtaba Rouhani/ TJMCS Vol .2 No.3 (2011) 559-564
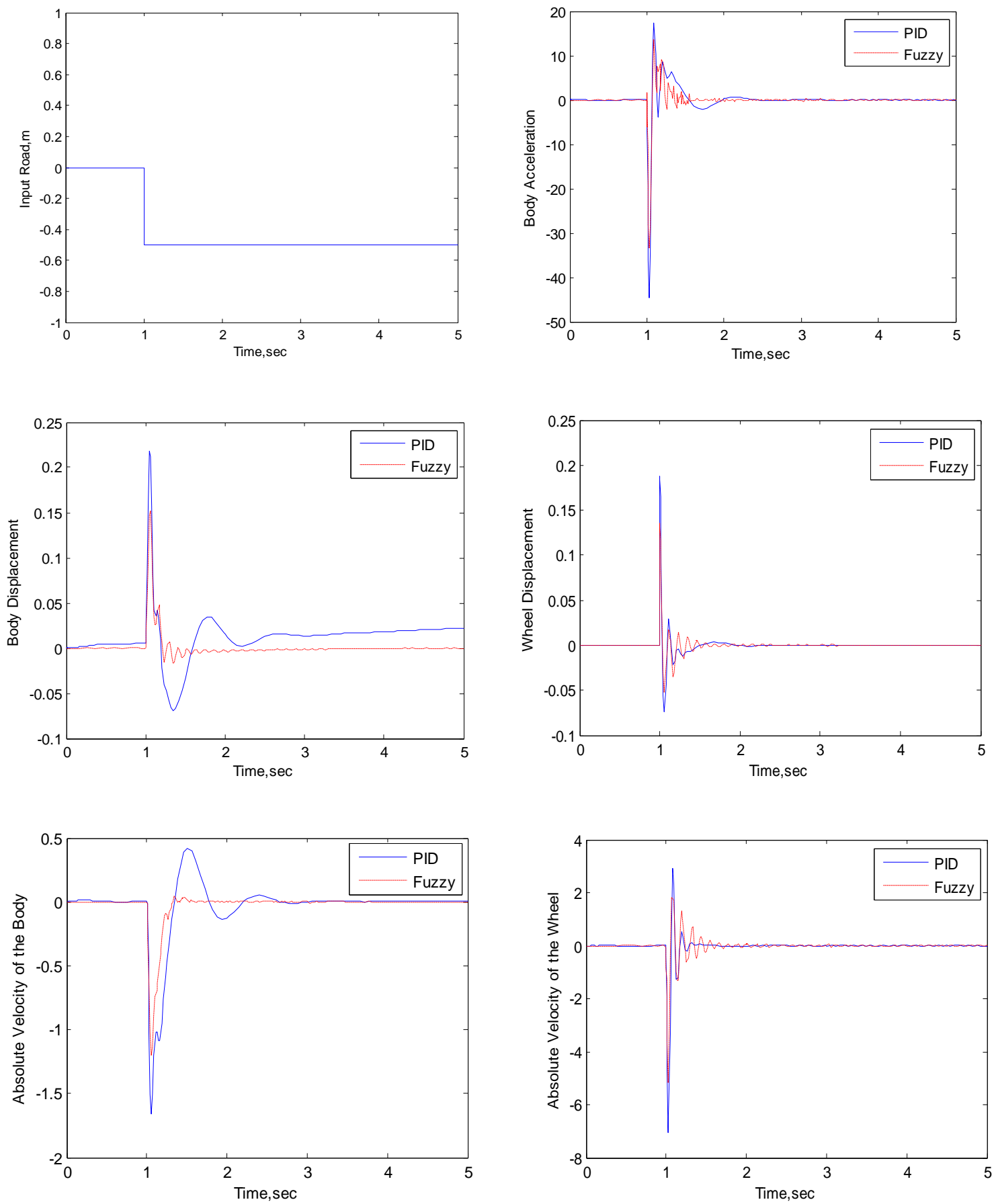

Figure 2. Simulation Results

\section{Conclusion}

Simulation results showed Fuzzy control is very effective and can be used in vehicles that will be manufactured in future. In this paper, the new active suspension control system is proposed to achieve both ride comfort and good handling. The results of the active suspension system based on 
Nemat Changizi , Modjtaba Rouhani/ TJMCS Vol .2 No.3 (2011) 559-564

the fuzzy logic controller also show the improved stability of the one-quarter-car model. The fuzzy logic suspension performed as well as and usually better than the PID controller [14].

\section{References}

[1] Mendel, J. M., March 1995, "Fuzzy Logic Systems for Engineering: A Tutorial." Proceedings of the IEEE, Vol. 83; No. 3; pp .345-377.

Schwartz, D. G., et al, April 1994, "Applications of Fuzzy Sets and Approximate Reasoning," Proceedings of IEEE, Vol. 82; No. 4; pp. 482-497.

Cherry, A. S. and R. P. Jones, March 1995, "Fuzzy logic control of an automotive suspension system," IEEE Proceedings. Control Theory and Applications, Vol. 142; No. 2; pp. 149-160 Ro, P. I., et al, 1993, "An Active Suspension using Fuzzy logic control, " 1993 American Control Conference Proceedings, Vol. 3; pp. 2252-2253

H .Chen, Z- .Y .Liu, P-.Y .Sun, "Application of Constrained H_Control to Active Suspension Systems on Half-Car Models", Journal of Dynamic Systems, Measurement, and Control, Vol .127 /353, SEP.2005.

[6] D.A .Crolla and A.M.A .Aboul Nour, "Theoretical comparisons of various active suspension systems in terms of performance and power requirements", Proceedings of IMecE Conference on Advanced Suspensions, C420/88:1-9, 24-25 October 1988.

[7] R.S .Sharp and S.A .Hassan, "On the performance capabilities of active automobile suspension systems of limited bandwidth", Vehicle System Dynamics, 16:213-225, 1987.

[8] P.G .Wright and D.A .Williams, "The case for an irreversible active suspension system", SAE, Transactions, J .of Passenger Cars, Sect .6, pages 83-90, 1989.

[9] R.A .Williams, A .Best, and I.L. "Crawford .Refined low frequency active suspension", Int .Conf .on Vehicle Ride and Handling, Proc.ImechE, C466/028:285-300, 1993.

[10] D .Hrovat ."A class of active LQG optimal actuators" .Automatica, 18:117-119, 1982.

[11] M.C .Smith and G.W .Walker ."Performance limitations and constraints for active and passive suspension :a mechanical multi-port approach. Vehicle System Dynamics", 33:137-168, 2000.

[12] R.J .Dorling .Integrated Control of Road Vehicle Dynamics .PhD thesis, Cambridge University, April 1996. [13] Ayman A .Aly, H .Ohuchi and A .Abo-Ismail . "A Cross Coupled Intelligent Fuzzy Controller of A 2 DOF Electro-Hydraulic Servo System", Conference of Fluid Power System, Akita, JAPAN, 2000. [14] M. M. M. Salem, and Ayman A. Aly. "Fuzzy Control of a Quarter-Car Suspension System" , World Academy of Science, Engineering and Technology 53, 2009. 